\title{
Quantificação do banco de sementes de plantas daninhas sob diferentes sistemas de manejo do solo
}

\author{
Ana Karyne Pereira MELOํㅗ , José Anchieta Alves ALBUQUERQUE ${ }^{1 *}$, Raphael Henrique da Silva SIQUEIRA², \\ Edmilson Evangelista da SILVA ${ }^{3}$, Roberto Dantas de MEDEIROS ${ }^{3}$, Leandro Torres de SOUZA ${ }^{1}$, \\ Anderson Carlos de Melo GONÇALVES ${ }^{1}$
}

\author{
${ }^{1}$ Programa de Pós-Graduação em Agronomia, Universidade Federal de Roraima, Boa Vista, RR, Brasil. \\ 2Instituto Federal de Roraima, Amajari, RR, Brasil. \\ ${ }^{3}$ Empresa Brasileira de Pesquisa Agropecuária, Boa Vista, RR, Brasil. \\ *E-mail: anchietaufrr@gmail.com \\ (ORCID: 0000-0003-4151-1192; 0000-0003-4391-258X; 0000-0002-8300-5928; 0000-0002-6454-1506; \\ 0000-0002-5601-049X; 0000-0002-6970-2671; 0000-0003-4151-1192)
}

Recebido em 16/10/2020; Aceito em 29/08/2021; Publicado em 20/09/2021.

\begin{abstract}
RESUMO: A composição, dinâmica e longevidade do banco de sementes do solo é variável em função do sistema de manejo, condições climáticas e espécies de plantas daninhas presentes. Desse modo, objetivou-se quantificar o banco de sementes de plantas daninhas do solo sob diferentes sistemas de manejo do solo. O experimento foi realizado em área de cerrado, no campo experimental da Embrapa e posteriormente em casa de vegetação da Universidade Federal de Roraima, Boa Vista, Roraima, Brasil. Foi utilizado delineamento inteiramente casualizado em esquema fatorial $5 \times 4 \times 2$ com quatro repetições. Os tratamentos consistiram do uso associado entre cinco diferentes sistemas de manejo do solo (vegetação nativa, cultivo mínimo, sistema de plantio direto, sistema convencional e sistema convencional com rotação de cultura), quatro profundidades de solo $(0-5 ; 5-10 ; 10-15$ e $15-20 \mathrm{~cm})$ e duas amostras de solo (indeformada e deformada). O sistema de plantio direto mostra-se eficiente no controle de plantas daninhas, pois o número de germinantes é inferior ao observado no sistema convencional, convencional com rotação e vegetação nativa. $O$ maior número de germinantes são encontradas nas amostras deformadas e nas profundidades 0-5 e 5-10 cm do solo.
\end{abstract}

Palavras-chaves: sistemas de cultivo; cerrado de Roraima; plantas infestantes.

\section{Quantification of the weed seed bank under different soil management systems}

\begin{abstract}
The composition, dynamics and longevity of the soil seed bank is variable depending on the management system, climatic conditions and weed species present. Thus, the objective was to evaluate the quantification of the seed bank of weeds in the soil under different soil management systems. The experiment was carried out in a cerrado area, in the Embrapa experimental field and later in the greenhouse of the Agronomy course at the Federal University of Roraima, Boa Vista, Roraima, Brasil. A completely randomized design in a $5 \times 4 \times 2$ factorial scheme with four replications was used. The treatments consisted of the associated use between five different soil management systems (native vegetation, minimum cultivation, no-tillage system, conventional system and conventional system with crop rotation), four soil depths $(0-5 ; 5-10 ; 10-15$ and 15 20) $\mathrm{cm}$ and two soil samples (unformed and deformed). The no-tillage system proved to be efficient in the control of weeds, since the number of germinants was lower than that observed in the conventional, conventional system with rotation and native vegetation. The greatest number of germinants were found in the deformed samples and at depths $0-5$ and $5-10 \mathrm{~cm}$ from the soil.
\end{abstract}

Keywords: cultivation systems; cerrado of Roraima; weeds.

\section{INTRODUÇÃO}

Com práticas agrícolas inadequadas e consequente remoção da cobertura vegetal, o solo é exposto à ação direta das condições climáticas, e, quando submetido à intensa atividade de cultivo, há alterações sobre os processos físicos, químicos e biológicos, modificando sua qualidade (PORTUGAL et al., 2012). Em contrapartida, a agricultura sustentável é dada pelo manejo e conservação dos recursos naturais de modo tecnicamente apropriado, economicamente viável e socialmente aceitável.

Nesse contexto, a adoção de sistemas conservacionistas como plantio direto e cultivo mínimo vem ganhando destaque como alternativa para solucionar alguns problemas nas lavouras. Um dos problemas é o controle de plantas daninhas que acarreta elevados custos à produção agrícola (LOUSADA; ESTEVES, 2017).

Qualquer mudança no sistema de produção agrícola provoca alterações ambientais, que, com frequência, causam grande impacto no tamanho da população e diversidade de espécies de plantas daninhas, pois atuam como fator ecológico não periódico (SOARES, 2011; TEIXEIRA JUNIOR et al., 2020). A adoção de práticas conservacionistas influenciam as populações de plantas daninhas de maneira 
diferente no perfil do solo (CHAUHAN et al., 2012; SCHWARTZ et al., 2015; MELO et al., 2021).

O banco de sementes tem a função de assegurar a perpetuação das espécies. Essa perpetuação se dá através de mecanismos ligados a semente, como dormência, longevidade e viabilidade, que permitem que as mesmas permaneçam por longos períodos nas diversas profundidades do solo (LACERDA et al., 2012).

O banco de sementes e as plantas que não são eliminadas com as práticas de manejo constituem as principais fontes de infestações futuras de plantas daninhas nas culturas (LACERDA et al., 2011).

Assim, no caso das lavouras contínuas, a rotação de culturas e o preparo do solo podem modificar a composição e a densidade dos bancos de sementes (GOULART et al., 2019). Deste modo, o reconhecimento da importância da qualidade física e química do solo, em termos agronômicos, bem como o conhecimento da composição e da dinâmica dos bancos de sementes pode contribuir para o aperfeiçoamento do manejo em diferentes sistemas de cultivo.

Objetivou-se com este trabalho quantificar o número de germinantes viáveis no banco de sementes de plantas daninhas em área submetida a cinco sistemas de manejo do solo.

\section{MATERIAL E MÉTODOS}

A pesquisa compreendeu um experimento do Projeto Sistema Plantio Direto (2015/2018) (Tabela 1) conduzido no ano agrícola de 2018, inicialmente, no campo experimental Água Boa da Embrapa Roraima, no município de Boa Vista - RR, cujas coordenadas geográficas de referência são registradas a $02^{\circ} 39^{\prime} 00^{\prime}$ de latitude, $60^{\circ} 49^{\prime} 40^{\prime \prime}$ de longitude e $90 \mathrm{~m}$ de altitude e posteriormente em casa de vegetação no Centro de Ciências Agrárias da Universidade Federal de Roraima (UFRR), município de Boa Vista, Roraima, sendo as coordenadas geográficas de referência $2^{\circ} 49^{\prime} 11^{\prime \prime}$ de latitude, $60^{\circ} 40^{\prime} 24$ " de longitude e de $90 \mathrm{~m}$ de altitude.

O clima da região, conforme Koppen, é classificado como tropical chuvoso, com médias anuais de precipitação, umidade relativa e temperatura de $1667 \mathrm{~mm}, 70 \%$ e $27,4^{\circ} \mathrm{C}$, respectivamente, apresentando período chuvoso com início em abril e término em setembro. Os dados de precipitação pluviométrica e de temperatura média mensais, coletados durante o período experimental, estão representados na Figura 1.

O solo foi classificado como ARGISSOLO AMARELO Distrocoeso textura média (EMBRAPA, 2018).

A pesquisa foi realizada no ano agrícola de 2018, o delineamento experimental utilizado foi inteiramente casualizado em esquema fatorial $5 \times 4 \times 2$ e quatro repetições com cada parcela medindo $10 \mathrm{~m}^{2}$. Os tratamentos consistiram do uso associado entre cinco diferentes sistemas de manejo do solo (vegetação nativa, cultivo mínimo, sistema plantio direto, sistema convencional e convencional com rotação de cultura), quatro profundidades de solo (0-5; 5-10; $10-15$ e $15-20 \mathrm{~cm}$ ) e duas amostras de solo (indeformada e deformada).

Tabela 1. Esquema de cultivo do experimento no campo experimental Água boa, no município de Boa Vista, Roraima. Table 1. Experimental cultivation scheme in the Água Boa experimental field, in the municipality of Boa Vista, Roraima.

\begin{tabular}{|c|c|c|c|c|c|}
\hline & & \multicolumn{4}{|c|}{ Ano } \\
\hline Sistema de Cultivo & Tratamento & 2015 & 2016 & 2017 & 2018 \\
\hline Plantio direto & 1 & Soja + Brachiaria & Milho+Brachiaria & Soja+Brachiaria & Soja+Brachiaria \\
\hline Cultivo mínimo & 2 & Soja + Brachiaria & Soja+Brachiaria & Soja + Brachiaria & Soja+Brachiaria \\
\hline $\begin{array}{l}\text { Plantio convencional } \\
\text { com rotação }\end{array}$ & 3 & Soja+Brachiaria & Milho+Brachiaria & Soja+Brachiaria & Soja+Brachiaria \\
\hline Plantio convencional & 4 & Soja & Soja & Soja & Soja \\
\hline Vegetação nativa & 5 & Pousio & Pousio & Pousio & Pousio \\
\hline
\end{tabular}

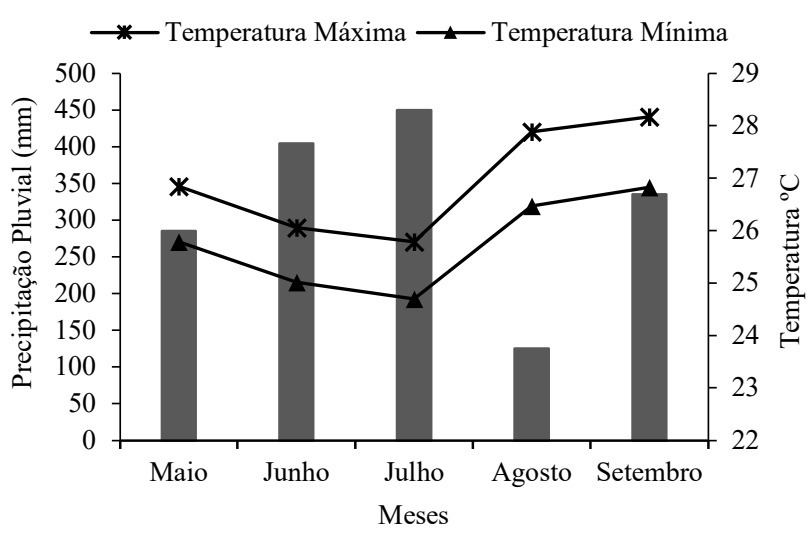

Figura 1. Precipitação pluviométrica $(\mathrm{mm})$ e temperatura máxima e mínima $\left({ }^{\circ} \mathrm{C}\right)$ mensal entre maio e setembro de 2018. Boa Vista, Roraima, 2020. Fonte: INMET.

Figure 1. Rainfall (mm) and monthly maximum and minimum temperature $\left({ }^{\circ} \mathrm{C}\right)$ between May and September 2018. Boa Vista, Roraima, 2020. Source: INMET.
No experimento foi utilizado a metodologia de emergência das sementes em solo, que requer menos trabalho e detecta a fração de sementes que germina.

a) Amostras deformadas de solo: as amostras de solo foram obtidas nas entrelinhas e linhas de plantio através de quatro amostras de solo composta por 12 sub amostras cada, nas profundidades de 0-5; 5-10,10-15 e 15-20 cm do solo com amostrador de diâmetro de $5 \mathrm{~cm}$ (ROBERTS; NEILSON, 1982). Totalizando 48 amostras por parcelas. As amostras foram destorroadas em peneira com malha de $6 \mathrm{~mm}$ e acondicionadas em bandejas plásticas $(25 \mathrm{~cm} \times 40 \mathrm{~cm} \times 7 \mathrm{~cm})$. As bandejas foram mantidas em casa de vegetação com umidade próxima a capacidade de campo, irrigadas duas vezes ao dia.

b) Amostras indeformadas de solo: as amostras de solo foram obtidas nas entrelinhas e linhas de plantio nas profundidades de 0-5; 5-10,10-15 e 15-20 cm do solo através de um amostrador feito com cano cilíndrico com base inferior em forma de bizel, com $12 \mathrm{~cm}$ de diâmetro e $5 \mathrm{~cm}$ de profundidades. Após coleta foi adicionado na extremidade inferior do cano PVC tecido específico para drenagem da 
água. Os canos foram mantidos em casa de vegetação com umidade próxima a capacidade de campo, irrigadas duas vezes ao dia.

A variável avaliada foram as plântulas resultantes da germinação que após três meses foram contadas e identificadas por meio de literatura específica (LORENZI, 2000; MOREIRA; BRAGANÇA, 2010; LORENZI, 2014).

Os dados obtidos foram submetidos à análise de variância, determinando-se a significância através do teste $\mathrm{F}$ a $5 \%$ de probabilidade. Para a análise das variáveis utilizou-se o teste de Tukey a 5\% de probabilidade com o auxílio do programa estatístico SISVAR versão 5.1 (FERREIRA, 2011).

\section{RESULTADOS}

O manejo do solo com sistema de plantio direto e cultivo mínimo proporcionaram menor número médio de germinantes por metro quadrado (165 e 217,5 respectivamente), diferindo do sistema convencional que apresentou o maior número $(649,3)$ (Tabela 2). A presença de resíduos vegetais sobre a superfície do solo no sistema de plantio direto age diretamente na germinação e emergência de plantas daninhas no banco de sementes do solo. Quanto a profundidade, a média do número de germinantes do banco de semente do solo de plantas daninhas nas profundidades de $0-5 ; 5-10 \mathrm{~cm}$ do solo não diferiram estatisticamente $\mathrm{e}$ foram maiores que para as profundidades de $10-15 ; 15-20 \mathrm{~cm}$ (Tabela 2).

Tabela 2. Número de germinantes do banco de semente de plantas daninhas nos diferentes sistemas de manejo do solo sob diferentes profundidades, Boa Vista, RR, 2020.

Table 2. Number of germinants from the weed seed bank in different soil management systems at different depths, Boa Vista, RR, Brazil, 2020.

\begin{tabular}{cccccc}
\hline Sistema de Cultivo & \multicolumn{5}{c}{ Profundidade do solo $(\mathrm{cm})$} \\
\cline { 2 - 6 } & $0-5$ & $5-10$ & $10-15$ & $15-20$ & Média \\
\hline Plantio direto & 190,0 & 190,0 & 145,0 & 135,0 & $165,0 \mathrm{c}$ \\
Cultivo mínimo & 257,5 & 265,0 & 190,0 & 157,5 & $217,5 \mathrm{c}$ \\
Convencional com rotação & 415,0 & 375,0 & 327,5 & 270,0 & $346,8 \mathrm{~b}$ \\
Convencional & 680,0 & 707,5 & 630,0 & 580,0 & $649,3 \mathrm{a}$ \\
Vegetação nativa & 425,0 & 387,5 & 350,0 & 355,0 & $379,3 \mathrm{~b}$ \\
\hline Média & $393,5 \mathrm{a}$ & $385,0 \mathrm{a}$ & $328,4 \mathrm{~b}$ & $299,5 \mathrm{~b}$ & - \\
\hline
\end{tabular}

Médias seguidas pela mesma letra minúscula não diferem entre si pelo teste de Tukey, a $5 \%$ de probabilidade

Para o número médio de germinantes do banco de sementes de plantas daninhas houve interação significativa entre os sistemas de manejo do solo e as amostras de solo (Tabela 3). Em relação as amostras indeformadas, de modo geral, o sistema convencional foi estatisticamente superior ao cultivo mínimo e sistema de plantio direto, porém foi igual ao sistema convencional com rotação de culturas e vegetação nativa (Tabela 3). O cultivo mínimo foi estatisticamente igual ao sistema convencional com rotação de cultura, vegetação nativa e sistema de plantio direto. O sistema de plantio direto mostrou-se eficiente no controle de plantas daninhas, pois o número de germinantes foi inferior ao observado no sistema convencional, sistema convencional com rotação de cultura e vegetação nativa (Tabela 3).

Tabela 3. Número de germinantes do banco de semente e plantas daninhas nos diferentes sistemas de manejo do solo sob diferentes amostras de solo, Boa Vista, RR, 2020.

Table 3. Number of seed bank germinants and weeds in different soil management systems under different soil samples, Boa Vista, RR, 2020.

\begin{tabular}{lccc}
\hline \multirow{2}{*}{ Sistema de Cultivo } & \multicolumn{2}{c}{ Amostra de solo } & \multirow{2}{*}{ Média } \\
\cline { 2 - 3 } & Indeformada & Deformada & \\
\hline Plantio direto & $53,0 \mathrm{Cb}$ & $165,0 \mathrm{Da}$ & 109 \\
Cultivo mínimo & $83,0 \mathrm{BCb}$ & $217,0 \mathrm{Ca}$ & 150 \\
Convencional com & $102,0 \mathrm{ABb}$ & $346,0 \mathrm{Ba}$ & 275 \\
rotação & $135,0 \mathrm{Ab}$ & $649,0 \mathrm{Aa}$ & 392 \\
Convencional & $100,0 \mathrm{ABb}$ & $379,0 \mathrm{Ba}$ & 289,5 \\
\hline
\end{tabular}

$\frac{\text { Média }}{\text { Médias seguidas pela mesma letra minúscula na linha e maiúscula na coluna }}$ não diferem entre si pelo teste de Tukey, a $5 \%$ de probabilidade

Para as amostras deformadas, o sistema convencional apresentou maior número de germinantes (649 plântulas por metro quadrado), seguido da vegetação nativa e sistema convencional com rotação de cultura (379 e 346 plântulas por metro quadrado respectivamente) que não diferiram estatisticamente. $\mathrm{O}$ sistema de plantio direto apresentou menor número de germinantes (165 plântulas por metro quadrado) (Tabela 3).

Em todos os sistemas de manejo do solo avaliados, as amostras deformadas apresentaram maior número de germinantes de plantas daninhas por metro quadrado em relação as amostras indeformadas, diferindo assim estatisticamente. Essa maior infestação de plantas daninhas pode ser explicada devido ao maior grau de perturbação do solo nas amostras deformadas.

Não houve diferença estatística no número de germinantes do banco de semente do solo de plantas daninhas das amostras indeformadas nos diferentes níveis de profundidades do solo. Nas amostras deformadas as profundidades $0-5$ e $5-10 \mathrm{~cm}$ do solo não diferiram estatisticamente e apresentaram em média 393 e 385 germinantes, respectivamente, seguido das profundidades $10-15$ e $15-20 \mathrm{~cm}$ do solo que não diferiram estatisticamente e apresentaram os menores números de germinantes de plantas daninhas (Tabela 4).

Tabela 4. Número de germinantes do banco de semente de plantas daninhas nas diferentes profundidades sob diferentes amostras de solo, Boa Vista, RR, 2020.

Table 4. Number of germinants from the weed seed bank at different depths under different soil samples, Boa Vista, RR, 2020.

\begin{tabular}{lccc}
\hline \multirow{2}{*}{ Profundidade } & \multicolumn{2}{c}{ Amostra de solo } & \multirow{2}{*}{ Média } \\
\cline { 2 - 3 } & Indeformada & Deformada & \\
\hline $05 \mathrm{~cm}$ & $111,0 \mathrm{Ab}$ & $393 \mathrm{Aa}$ & 252 \\
$5-10 \mathrm{~cm}$ & $104,0 \mathrm{Ab}$ & $385 \mathrm{Aa}$ & 296,5 \\
$10-15 \mathrm{~cm}$ & $87,0 \mathrm{Ab}$ & $328 \mathrm{Ba}$ & 207,5 \\
$15-20 \mathrm{~cm}$ & $77,0 \mathrm{Ab}$ & $299 \mathrm{Ba}$ & 188 \\
\hline \multicolumn{1}{c}{ Média } & 97,75 & 351,25 & \\
\hline
\end{tabular}

Médias seguidas pela mesma letra minúscula na linha e maiúscula na coluna não diferem entre si pelo teste de Tukey, a $5 \%$ de probabilidade. 


\section{DISCUSSÃO}

A rotação de culturas, juntamente com a cobertura permanente e o mínimo revolvimento do solo, compõe os princípios básicos do sistema de plantio direto. A ausência dessa prática acarreta o surgimento de alterações de ordem química, física e biológica no solo, que podem comprometer a estabilidade do sistema produtivo. Dentre as alterações observadas se destaca o acréscimo da infestação de plantas daninhas (FRANCHINI et al., 2011).

A presença de resíduos vegetais sobre a superfície do solo no sistema de plantio direto age diretamente na germinação e emergência de plantas daninhas no solo. As espécies de plantas de cobertura e a quantidade de resíduos produzidos podem afetar o crescimento e o desenvolvimento das plantas daninhas, por meio da liberação de compostos alelopáticos e/ou pelo efeito físico, impedindo assim a sobrevivência das sementes germinadas na superfície do solo (GOMES JR.; CHRISTOFFOLETI, 2008).

No sistema de plantio direto, onde as sementes de plantas daninhas estão concentradas na superfície do solo, ocorre diminuição do banco de sementes, pela indução da germinação, perda de viabilidade, predação e parasitismo (MONQUERO; CHRISTOFFOLETI, 2005).

Segundo YENISH et al. (1992), a concentração das sementes de plantas daninhas diminui de forma logarítmica com o aumento da profundidade do solo.

Segundo Ronchi et al. (2010) o conhecimento da profundidade na qual a plântula é capaz de emergir pode permitir uma melhor adoção de práticas de manejo a ser utilizada.

Trabalhos realizados por Lessa et al. (2012) avaliando sementes de Emilia coccínea (Asteraceae) em várias profundidades, verificou que a percentagem de germinação e o índice de valor de emergência foi negativamente afetado com o enterrio abaixo de $5 \mathrm{~cm}$. Concluíram ainda que a capacidade de emergência das plântulas é superior quando as sementes se encontram na superfície do substrato.

Monquero et al. (2012) testaram uma planta daninha bastante comum em áreas de plantio pelo o Brasil, a espécie capim camalote (Rottboellia exaltata) em diferentes profundidades de semeadura $(0,0,5,1,5,10,12,15$ e $20 \mathrm{~cm})$. A maior emergência ocorreu até a profundidade de 5,0 cm.

Trabalhos com resultados similares com outras espécies de plantas daninhas foram relatados por Luz et al. (2014), Zuffo et al. (2014) e Alberguini; Yamashita, (2010).

Comumente o banco de sementes, em torno de $60 \%$ concentra-se nas camadas mais superficiais do solo (MENEZES et al., 2019), como observado neste trabalho.

As sementes localizadas na superfície do solo ficam mais facilmente sujeitas às variações de temperatura e umidade, auxiliando na quebra da dormência (NOGUEIRA et al., 2012), o que pode explicar as maiores germinações nestas camadas.

Além disso, sistemas de cultivo que promovem o revolvimento do solo, aumentam a exposição de sementes à luz, sendo este um dos fatores essenciais para a germinação; contudo, existem espécies que germinam também na ausência dela, algumas por adaptação das condições adversas do ambiente, outras por condições fisiológicas. Segundo Carvalho; Nakagawa (2000), a luz é necessária para a germinação de algumas espécies infestantes, mas não é considerada fator fundamental para as sementes nãodormentes. A resposta das sementes ao estímulo luminoso é denominada fotoblastia. Quando a luz promove a germinação, o fotoblastismo é positivo, e quando a germinação é promovida na ausência da luz, o fotoblastismo é negativo. Esse efeito diferencial da luz, regulado pelo fitocromo, cujos mecanismos são complexos e pouco conhecidos, apresenta grande diversidade de respostas (YAMASHITA et al., 2010).

O conhecimento das características dos bancos de sementes do solo como, sua variabilidade espacial, número de espécies, quantidade de sementes e distribuição destas no perfil do solo, permite projeções sobre a velocidade e composição florística dos estádios iniciais da regeneração e pode fornecer uma estimativa do potencial da regeneração após algum tipo de distúrbio (COSTA et al., 2009).

A longevidade do banco de sementes do solo é variável em função das condições climáticas, profundidade de enterrio, espécies e tipo de solo. De acordo com Orzari et al. (2013), a não emergência de plântulas das espécies infestantes é causada pela maior profundidade em que se encontram as sementes.

Nas diferentes profundidades as amostras deformadas apresentaram o maior número de germinantes de plantas daninhas em relação as amostras indeformadas. Isso pode ser explicado devido ao maior grau de perturbação no solo nas amostras deformadas o que propicia ambiente favorável para a germinação das sementes, pois estas estão mais susceptíveis as condições climáticas o que propicia sua germinação.

Assim, esses resultados podem ser usados para práticas de manejo preventivo das sementes que necessitam de luz para germinar; Maior exposição à luz por sementes de plantas daninhas, em áreas de cultivo, ocorre quando elas estão em menores profundidades. Em maiores profundidades, não há incidência de luz em quantidade suficiente para promover a germinação. Assim, a dinâmica das populações de plantas daninhas em sementes fotoblásticas positivas é muito dependente do posicionamento desses diásporos no perfil do solo, bem como da existência de cobertura vegetal na superfície do terreno (YAMASHITA et al., 2010).

\section{CONCLUSÕES}

O banco de sementes do solo no sistema de plantio direto apresenta menor número de germinantes, o que torna este sistema eficaz no controle de plantas daninhas.

O banco de sementes das amostras deformadas que sofrem maiores graus de perturbações apresenta maior número de germinantes de plantas daninhas.

As sementes estabelecidas nas profundidades até $10 \mathrm{~cm}$ do solo são mais susceptíveis a germinação.

\section{REFERÊNCIAS}

ALBERGUINI, A. L.; YAMASHITA, O. M. Profundidade de semeadura e presença de palha afetam a emergência de plântulas de Vernonia ferruginea. Planta Daninha, Viçosa, v. 28, p. 1005-1013, 2010.

ALBUQUERQUE, J. A. A.; MELO, V. F.; SOARES, M. B.; FINOTO, L. F.; SIQUEIRA, R. H. S.; MARTINS S. A. Fitossociologia e características morfológicas de plantas daninhas após cultivo de milho em plantio convencional no cerrado de Roraima. Revista Agro@mbiente, Boa Vista, v. 7, n. 3, p. 313-321, 2013. DOI: http://dx.doi.org/10.18227/1982-8470ragro.v7i3.1392

CARVALHO, N. M.; NAKAGAWA, J. Sementes: ciência, tecnologia e produção. Jaboticabal: FUNEP, 2000. 588 p. 
CHAUHAN, B. S.; SINGH, R. G.; MAHAJAN, G. Weed ecology and management in conservation agriculture: a review. Crop Protection, v. 38, p. 57-65, 2012. DOI: 10.1016 / j.cropro.2012.03.010

COSTA, C. J.; ARAÚJO, R. B.; BÔAS, H. D. C. VILLAS. Tratamentos para a superação de dormência em sementes de Brachiaria bumidicola (Rendle) Schweick. Pesquisa Agropecuária Tropical, Goiânia, v. 41, n. 4, p. 519-524, 2011.

COSTA, J. R.; MITJA, D.; FONTES, J. R. A. Bancos de sementes de plantas daninhas em cultivos de mandioca na Amazônia Central. Planta Daninha, Viçosa, v. 27, p. 665-671, 2009. DOI: https://doi.org/10.1590/S010083582009000400004

EMBRAPA. Sistema Brasileiro de Classificação de Solos. 5 ed. Rio de Janeiro: Embrapa Solos, 2018. 356p.

FERREIRA, D. F. Sisvar: a computer statistical analysis system. Ciência e Agrotecnologia, Lavras, v. 35, n. 6, p. 1039-1042, 2011.2 DOI: https://doi.org/10.1590/S1413-70542011000600001

FRANCHINI, J. C.; COSTA, J. M. da; TORRES, H. D. E. Importância da rotação de culturas para a produção agrícola sustentável no Paraná. Londrina: Embrapa Soja, 2011. 50p. (Documento, 327).

GOMES JR, F. G.; CHRISTOFFOLETI, P. J. Biologia e manejo de plantas daninhas em áreas de plantio direto. Planta Daninha, Viçosa, v. 26, p. 789-98, 2008.

GOULART, F. D. A. P.; ANDRES, A.; AGOSTINETTO, D.; SCHMITZ, M. F.; MARTINS, M. B. Rotação de culturas e preparo do solo sobre o banco de sementes de plantas daninhas em terras baixas. Revista Brasileira de Herbicidas, Londrina, v. 18, n. 4, p. 680-691, 2019. DOI: https://doi.org/10.7824/rbh.v18i4.680

LACERDA, K. L. P.; CORDEIRO, M. A. S.; VERGINASSI, A.; SALGADO, F. H. M. Organic carbon, biomass and microbial activity in an Oxisol under different management systems. Revista Ciências Agrárias, Lisboa, v. 56., p. 249-254, 2011. DOI: http://dx.doi.org/10.4322/rca.2013.036

LUZ, F. N.; YAMASHITA, O. M.; FERRARESI, D. A.; CARVALHO, M. A. C.; CAMPOS, O. R.; KOGA, P. S.; MASSAROTO, J. A. Interferência de luz, temperatura, profundidade de semeadura e palhada na germinação e emergência de Murdannia nudiflora. Comunicata Scientiae, Bom Jesus, v. 5, n. 1, p. 26-33, 2014. DOI: https://doi.org/10.14295/cs.v5i1.238

TRINDADE LESSA, B. F.; FERREIRA, V. M.; ARAÚJO NETO, J. C.; SOUZA, R. C. Germinação de sementes de Emilia coccinea (Sims) G. DON em função da luminosidade, temperatura, armazenamento e profundidade de semeadura. Semina: Ciências Agrárias, Londrina, v. 34, n. 1, p. 3193-3204, 2013. DOI: 10.5433/1679-0359.2013v34n6Supl1p3193

LINDQUIST, J. L.; MAXWELL, B. D. The horizontal dispersal pattern of weed seed surrogates by farms machinery. Weed Science Society, v. 46, p. 108-109, 1991.

LORENZI, H. Manual de Identificação e Controle de Plantas Daninhas - Plantio Direto e Convencional. 7 ed. Nova Odessa: Instituto Platarum, 2014. 379p.

LORENZI, H. Plantas Daninhas do Brasil - terrestres, aquáticas, parasitas e tóxicas. 3 ed. Nova Odessa: Instituto Platarum, 2000. 608p.
MONQUERO, P. A.; HIJANO, N.; ORZARI, I.; SANTOS SABBAG, R.; SILVA HIRATA, A. C. Profundidade de semeadura, $\mathrm{pH}$, textura e manejo da cobertura do solo na emergência de plântulas de Rottboellia exaltata. Semina: Ciências Agrárias, Londrina, v. 33, n. 1, p. 2799-2812, 2012. DOI: 10.5433/1679-0359.2012v33Supl1p2799

MOREIRA, H. J. da C.; BRAGANÇA, H. B. N. Manual de Identificação de Plantas Infestantes - Cultivos de Verão. Campinas: Ed. FMC, 2010. 642p.

LOUSADA L. L.; ESTEVES B. S. Banco de Sementes de Plantas Daninhas em Áreas de Cana-de-açúcar no Norte Fluminense. Revista FIMCA, Porto Velho, v. 4, p. 4958, 2017. DOI: https://doi.org/10.37157/fimca.v4i1.9

MELO, A. K. P.; ALBUQUERQUE, J. A. A.; SIQUEIRA, R. H. S.; SILVA, E. E.; MEDEIROS, R. D.; SOUZA, K. T. S.; SOUZA, L. T.; GONÇALVES, A. C. M.; SOARES, M. B. B. Occurrence of noxious weeds under different soil management systems. Applied Ecology and Environmental Research, v. 19, n. 3, p. 2061-2072, 2021. DOI: http://dx.doi.org/10.15666/aeer/1903_20612072

MENEZES, P. H. S.; ALBUQUERQUE, J. A. A.; SMIDERLE, J. O.; MEDEIROS, R. D.; ALVES, J. M. A.; GIANLUPPI, D. Occurrence of weeds in areas submitted to tillage managements for soybean cultivation in the Cerrado of Roraima. Planta Daninha, Viçosa, v. 37, e019193014, 2019. DOI: https://doi.org/10.1590/s0100-83582019370100079

NOGUEIRA, B. C. B.; SILVA, J. W. L.; BEZERRA, A. M. E.; FILHO, S. M. Efeito da temperatura e luz na germinação de sementes de Luetzelburgia auriculata (Alemão) Ducke-Fabaceae. Acta Botânica Brasileira, Brasília, v. 26, n. 4, p. 772-778, 2012. DOI: https://doi.org/10.1590/S0102-33062012000400006

ORZARI, I.; MONQUERO, P. A.; REIS, F. C.; ABBAG, R. S.; HIRATA, A. C. S. Germinação de espécies da família Convolvulaceae sob diferentes condições de luz, temperatura e profundidade de semeadura. Planta Daninha, Viçosa, v. 31, n. 1, p. 53-61, 2013. DOI: https://doi.org/10.1590/S0100-83582013000100006

PORTUGAL, A. F.; COSTA, O. D. V.; COSTA L. M. Propriedades físicas e químicas do solo em áreas com sistemas produtivos e mata na região da zona da mata mineira. Revista Brasileira de Ciência do Solo, Viçosa, v. 34 , n. 1 , p. 75-585, 2010. DOI: https://doi.org/10.1590/S0100-06832010000200032

ROBERTS, H. A.; NEILSON, J. E. Seed bank of soils under vegetable cropping in England. Weed Research, v. 22, n. 1, p. 13-16, 1982.

RONCHI, C. P.; SERRANO, L. A. L.; SILVA, A. A.; GUIMARÃES, O. R. Manejo de plantas daninhas na cultura do tomateiro. Planta Daninha, Viçosa, v. 8, n. 1, p. 215-228, 2010.

SCHWARTZ, L. M.; GIBSON, D. J.; GAGE, K. L.; MATTHEWS, J. L.; JORDAN, D. L.; OWEN, M. D.; YOUNG, B. G. Seedbank and weed field emergence in glyphosate resistant cropping systems in the United States. Weed Science, v. 63, n. 2, p. 425-439, 2015. DOI: 10.1614/WS-D-14-00089.1

SOARES, M. B. B.; FINOTO, E. L.; BOLONHEZI, D.; CARREGA, W. C.; ALBUQUERQUE, J. A. A.; PIROTTA, M. Z. Fitossociologia de plantas daninhas sob diferentes sistemas de manejo de solo em áreas de reforma de cana crua. Revista Agro@mbiente, Boa 
Vista, v. 5, n. 3, p. 173-181, 2011. DOI: 10.18227/19828470ragro.v5i3.594

TEIXEIRA JUNIOR, D. L.; ALVES, J. M. A.; ALBUQUERQUE, J. A. A.; ROCHA, P. R. R.; CASTRO, T. S.; BARRETO, G. F. Ocorrência de plantas daninhas na cultura do feijão-caupi sob quatro manejos na Amazônia Ocidental. Nativa, Sinop, v. 8, n. 3, p. $427-$ 435, $2020 . \quad$ DOI: https://doi.org/10.31413/nativa.v8i3.8949

YAMASHITA, O. M.; GUIMARÃES, S. C.; ALBUQUERQUE, M. C. F.; CARVALHO, M. A. C.; MASSAROTO, J. A.; KOGA, P. S.; CAMPOS, O. R. Germinação de sementes de duas espécies de Conyza em função da presença ou ausência de luz e interação com a adição de nitrato e ácido giberélico no substrato. Ambiência, Guarapuava, v. 12, n. 2, p. 655 - 666, 2016. DOI: 10.5935/ambiencia.2016.02.10

YENISH, J. P.; DOLL, J. D.; BUHLER, D. D. Effects of tillage on vertical distribution and viability of weed seed insoil. Weed Science, v. 40, n. 3, p. 429-433, 1992. https://doi.org/10.1590/S0100-83582008000400010

ZUFFO, A. M.; ANDRADE, F. R.; SILVA, L. M. A.; MENEZES, K. O.; SILVA, R. L.; PIAUILINO, A. C. Profundidade de semeadura e superação de dormência no crescimento inicial de sementes de Brachiaria dictyoneura (Fig. \& De Not.) Stapf (1919) cv. Llanero. Revista Ceres, Viçosa, v. 61, n. 6, p. 948-955, 2014. DOI: https://doi.org/10.1590/0034-737X20146106009 